\title{
Relation between sacral sparing and long term urological outcome in open spina bifida Pippa Oakeshot* and Gillian M Hunt
}

\author{
Address: Community Health Sciences St George's Hospital Medical School London SW17 ORE \\ Email: Pippa Oakeshot* - oakeshot@sghms.ac.uk \\ * Corresponding author
}

\author{
from 49th Annual Meeting of the Society for Research into Hydrocephalus and Spina Bifida \\ Barcelona, Spain, 29 June - 2 July 2005 \\ Published: 30 December 2005 \\ Cerebrospinal Fluid Research 2005, 2(Suppl I):S26 doi:I0.I I86/I743-8454-2-SI-S26
}

\section{Background}

The Cambridge Cohort of 117 patients born with open spina bifida provide information on causes of death and outcome to age 40 with no loss to follow up. We previously showed survival and long term prognosis were related to sensory level.

\section{Aims}

To examine the influence of sacral sparing on urological outcome. Sacral sparing was defined as intact sensation to pinprick in at least one dermatome in the saddle area S2S4.

\section{Design}

Prospective cohort study

\section{Materials and methods}

The cohort comprises 117 consecutive individuals with open spina bifida who were treated unselectively from birth in the Neurosurgical department at Addenbrooke's Hospital, Cambridge, England between 1963 and 1971. They have been reviewed six times by the same independent observer. Based on the results of meticulous neurological examination in infancy, we divided the group into those with and without sacral sparing and looked at the relation with long term outcome

\section{Results}

$33(28 \%)$ of the 117 individuals had sacral sparing. 10 (30\%) of them have died compared with 57 (68\%) of the 84 without sacral sparing $(\mathrm{p}<0.001)$. None of those with sacral sparing died of renal causes compared with $19 / 57$ $(33 \%)$ of those with no sacral sparing ( $p<0.001)$. Urological admissions during the teenage years were commoner in those with no sacral sparing: $19 / 42$ (45\%) compared with $2 / 26(8 \% \mathrm{p}=0.001)$. Urinary continence was closely related to sacral sparing at mean ages 4,9 and 25. Thus at age 25 16/25 (64\%) of those with sacral sparing were continent compared with $1 / 36(3 \%)$ of the remainder.

\section{Conclusion}

Although urological management has improved, it is likely that babies with open spina bifida who have sacral sparing will have a better long term outcome than those without in terms of overall survival, renal deaths, urological admissions and urinary continence. 